\title{
Evaluating Inoculation Methods to Infect Sugar Beet with Fusarium oxysporum f. betae and $F$. secorum
}

\author{
X. Lai, ${ }^{1}$ A. Qi, ${ }^{2}$ Y. Liu, ${ }^{1}$ L. E. Del Río Mendoza, ${ }^{1}$ Z. Liu, ${ }^{1}$ Z. Lin, ${ }^{3}$ and M. F. R. Khan ${ }^{1,4, \dagger}$ \\ ${ }^{1}$ Department of Plant Pathology, North Dakota State University, Fargo, ND 58108-6050, U.S.A. \\ ${ }^{2}$ School of Life and Medical Sciences, University of Hertfordshire, Hatfield, AL10 9AB, U.K. \\ ${ }^{3}$ Department of Agricultural and Biosystems Engineering, North Dakota State University, Fargo, ND 58108-6050, U.S.A. \\ ${ }^{4}$ University of Minnesota, St. Paul, MN, U.S.A.
}

\begin{abstract}
Minnesota and North Dakota combined contain 55\% of the sugar beet production area in the United States, contributing to $49 \%$ of the nation's sugar beet production in 2018. Fusarium diseases caused by Fusarium oxysporum $\mathrm{f}$. betae and F. secorum on sugar beet can cause significant reduction in both root yield and sucrose concentration and purity. The objective of this research was to identify an alternative artificial inoculation method to induce Fusarium diseases on sugar beet leaves and roots caused by both Fusarium spp. in greenhouse conditions to better aid in research efforts. We tested four inoculation methods, including barley to seed, barley to root, drenching, and cutting. and compared them with the conventional root-dipping inoculation method. The inoculation

method of placing Fusarium-colonized barley seed close to sugar beet seed (barley to seed) caused levels of symptom severities on both leaves and roots similar to the root-dipping method. Because the traditional root-dipping method involves a laborious transplant process, use of infected barley seed as inoculum may serve as an alternative method in the evaluation of host resistance and pathogen virulence among Fusarium diseases by Fusarium spp. on sugar beet at the seed or seedling stage.

Keywords: disease management, $F$. oxysporum f. betae, fungi, Fusariumcolonized barley seed, Fusarium secorum, root-dipping, sugar beet, techniques, vegetables
\end{abstract}

Sugar beet (Beta vulgaris L.) is a major source of global sucrose production, especially in temperate regions. The United States was the second-largest sugar beet producer in the world in 2017 (FAO 2017). In 2018, Minnesota and North Dakota accounted for 55\% of the sugar beet growing area and contributed $49 \%$ of the total sugar beet production in the United States (USDA-ERS 2019). Diseases caused by Fusarium spp. on sugar beet can reduce root yield and extractable sucrose (Hanson and Jacobsen 2009).

In the Red River Valley of North Dakota and Minnesota, Fusarium oxysporum f. betae (D. Stewart) W. C. Snyder \& H. N. Hansen and $F$. secorum are the pathogens most consistently associated with Fusarium diseases on sugar beet (Khan et al. 2009). Fusarium yellows. caused by $F$. oxysporum f. betae, was first reported in the Red River Valley in 2002 (Windels et al. 2005). The disease symptoms are a characteristic interveinal chlorosis, internal taproot vascular-discoloration without external appearance, and canopy wilt. In 2005, a new disease, Fusarium yellowing decline, caused by $F$. secorum, was first reported by Rivera et al. (2008) in Minnesota (Secor et al. 2014). Unlike $F$. oxysporum f. betae, only F. secorum causes seedling death, yellowing during early growing season, and petiole vascular discoloration (Burlakoti et al. 2012).

Effective artificial inoculation methods are necessary for the identification of sources of host resistance, host-pathogen interactions, and studies on disease control strategies (Das et al. 2015). The root-dipping inoculation method has been the standard method for evaluating $F$. oxysporum infection, which affects several plant species, including chickpea, tomato, cotton, and cucumber (Dowd et al. 2004; Maitlo et al. 2016; Rowe 1980; Vakalounakis 1996).

${ }^{\dagger}$ Corresponding author: M. F. R. Khan; mohamed.khan@ndsu.edu

Funding: This research was partially supported by the Sugarbeet Research and Education Board of Minnesota and North Dakota.

The author(s) declare no conflict of interest.

Accepted for publication 3 January 2020.

(C) 2020 The American Phytopathological Society
The root-dipping method has also been used to evaluate $F$. oxysporum f. betae on sugar beet (Hanson 2006). This same inoculation method has been used to study the effect of $F$. secorum on sugar beet (Burlakoti 2007; Rivera et al. 2008). The root-dipping inoculation method involves damaging the roots, allowing the pathogen to invade through wounds, avoiding a natural barrier at the epidermis (Eynck et al. 2009). Alternative inoculation methods which do not result in artificial wounding of the root such as the standard rootdipping method would be of value because they better simulate natural conditions during pathogen attempts at establishment. In this work, we tested four alternative inoculation methods to identify a more effective inoculation method for Fusarium disease evaluations.

\section{Materials and Methods}

Fungal isolates. Known pathogenic isolates $F$. oxysporum $\mathrm{f}$. betae F-19, isolated from Salem, OR in 2001, and provided by the United States Department of Agriculture-Agricultural Research Service Sugarbeet Research Unit, Fort Collins, CO, and F. secorum 78412-4, isolated from Sabin, Minnesota in 2007, and provided by Dr. G. A. Secor, North Dakota State University, Fargo, ND were used for this study.

Inoculum preparation. Liquid cultures were prepared using carboxymethylcellulose (CMC) medium. One liter of CMC medium contains $15 \mathrm{~g}$ of CMC sodium salt (Sigma-Aldrich), $1 \mathrm{~g}$ of ammonium nitrate (ACS reagent, $\geq 98 \%$; Sigma-Aldrich), $1 \mathrm{~g}$ of potassium phosphate monobasic (Sigma-Aldrich), $0.5 \mathrm{~g}$ of magnesium sulfate heptahydrate (ACS reagent, $\geq 98 \%$; Sigma-Aldrich), and $1 \mathrm{~g}$ of yeast extract (Sigma-Aldrich). All chemicals were dissolved in 1 liter of distilled water and autoclaved at $170 \mathrm{kPa}$ and $120^{\circ} \mathrm{C}$ for $20 \mathrm{~min}$. Fungal cultures were prepared by transferring hyphae from a long-term storage vial into 100-by-15-mm petri dishes (Falcon) containing full-strength potato dextrose agar (PDA) (Sigma-Aldrich) and incubating them under fluorescent light at room temperature $\left(24^{\circ} \mathrm{C}\right)$ for 1 week. Erlenmeyer flasks containing $200 \mathrm{ml}$ of CMC medium were inoculated with 20 pieces of $5-\mathrm{mm}^{2}$ plugs containing actively growing hyphae. The inoculated CMC medium was placed in a rotary shaker (MaxQ Shakers; Thermo Scientific) and incubated at $210 \mathrm{rpm}$ under soft white fluorescent light at $25^{\circ} \mathrm{C}$. After 7 days, the CMC medium was passed through two layers of Miracloth 
(Calbiochem, EMD Millipore Corporation) to collect spores. A hemocytometer (Propper Manufacturing Co., Inc.) was used to estimate the concentration. The spore suspension was adjusted to $5 \times 10^{4}$ spores $/ \mathrm{ml}$ with distilled water and used immediately.

Barley seed (nontreated) were used as a solid substrate. Fusariuminfested barley inoculum were produced following the same method used for producing Rhizoctonia solani-infested barley grains (Kirk et al. 2008; Noor and Khan 2014). Mixtures of $4.8 \mathrm{~g}$ of potato dextrose broth (Sigma-Aldrich), $200 \mathrm{ml}$ of barley, and $120 \mathrm{ml}$ of distilled water (5:3 barley/distilled water [ $\mathrm{vol} / \mathrm{vol}] \mathrm{ratio})$ were placed into 500 $\mathrm{ml}$ flasks (Pyrex) and autoclaved at $170 \mathrm{kPa}$ and $120^{\circ} \mathrm{C}$ for $30 \mathrm{~min}$, then left to cool to room temperature overnight. The initial inoculum was grown on PDA as described above, cut into $3-\mathrm{mm}^{2}$ plugs, and transferred into autoclaved flasks containing barley. One flask of barley was inoculated with plugs from one petri dish. Inoculated flasks were sealed, mixed every 2 days by hand shaking, incubated at room temperature for 2 weeks, and then air dried under a laminar flow hood for 2 days. The air-dried barley grains were stored at $4{ }^{\circ} \mathrm{C}$ until used. CFU were calculated for each isolate by grinding 50 grains in $100 \mathrm{ml}$ of autoclaved distilled water for 5 min using a blender. Three serial 1/10 dilutions were prepared and a total volume of $100 \mu \mathrm{l}$ from each dilution was plated onto 100-by-15-mm PDA plates with three replicates. The number of CFU was estimated after $24 \mathrm{~h}$ of incubation at room temperature.

Sugar beet plants and seed. This study was conducted in a greenhouse (Argus Control Systems, Ltd.) of the Agricultural Experiment Station of North Dakota State University in Fargo, ND, U.S.A. Three seeds of Fusarium spp.-susceptible variety Maribo 409 (Niehaus 2016) were planted in a plastic pot $(10 \times 10 \times 12 \mathrm{~cm}$; T. O. Plastic Inc.) filled with Sunshine Mix number 1 peat (Sun Gro Horticulture Ltd.). One teaspoon of Osmocote 15-9-12 fertilizer (3 to 4 months' formula) (Everris NA Inc.) was added and mixed to each pot before seeding. One week after planting, seedlings were thinned to one plant per pot. Greenhouse conditions were set to an average temperature of $24^{\circ} \mathrm{C}$ and $16-\mathrm{h}$ photoperiod. Plants were watered as needed. Threeweek-old sugar beet plants (at the four-leaf stage) were used for all inoculations except the barley to seed method, where sugar beet seed were used and which is described below.

To identify the most effective alternative inoculation method, five inoculation methods were evaluated: the conventional standard method (root-dipping), drench without injury (drenching), drench with injury (cutting), Fusarium-colonized barley seed placed next to sugar beet plants (barley seed to root), and Fusarium-colonized barley seed placed next to sugar beet seed at planting (barley to seed). After inoculation, all plants were kept in the greenhouse environment, set at a temperature of $24^{\circ} \mathrm{C}$ and a 16-h photoperiod, and watered as needed. Six replicates of individual plants and trays with 10 seeds each for each isolate were used. This experiment was performed using a completely randomized design two times.

Inoculation methods. Root-dipping (root-dipping). Three-weekold plants were carefully removed from their pots. Roots were washed with distilled water, dried with tissue paper, and soaked in a Fusarium spore suspension $\left(5 \times 10^{4}\right.$ spores $\left./ \mathrm{ml}\right)$ for $8 \mathrm{~min}$ (Hanson and Hill 2004). A 1\% CMC medium in distilled water was used as a control. After inoculation, plants were transplanted into wet plastic pots as described above. Old or yellow leaves were removed 3 days after inoculation (Hanson and Hill 2004).

Drenching without injury (drenching). Inoculation was conducted by pouring $20 \mathrm{ml}$ of Fusarium spore suspension $\left(5 \times 10^{4}\right.$ spores $\left./ \mathrm{ml}\right)$ uniformly across the soil surface of pots containing one 3 -week-old plant each (Maitlo et al. 2016). Control pots had 1\% CMC medium in distilled water poured instead of spore suspension.

Drenching with injury (cutting). To injure 3-week-old sugar beet roots, two longitudinal cuts about $10 \mathrm{~cm}$ deep were made about $1.3 \mathrm{~cm}$ away from opposite sides of each root using a knife sterilized in $75 \%$ ethanol. These two cuts were parallel to each other. Inoculation was performed the same way as drench inoculation without injury. The control plants were inoculated with $1 \% \mathrm{CMC}$ medium in distilled water.

Fusarium-colonized barley seed placed next to sugar beet plants (barley to root). Inoculation was conducted by placing one
Fusarium-colonized barley seed $1 \mathrm{~cm}$ away from the root and $2 \mathrm{~cm}$ below the soil surface, then covering the seed with Sunshine Mix number 1 peat for each sugar beet plant (Liu and Khan 2016). A sterilized barley seed without Fusarium infection was placed beside each plant in the control.

Fusarium-colonized barley seed placed next to sugar beet seed at planting (barley to seed). For this inoculation method, plastic trays $(28 \times 12 \times 12 \mathrm{~cm})$ were used, and fertilizer was added to potting soil as previously described. Ten sugar beet seeds were planted in 2-cmdeep furrows and one Fusarium-colonized barley seed was placed $1 \mathrm{~cm}$ to the side of each sugar beet seed, then covered with Sunshine Mix number 1 peat (Liu and Khan 2016). A sterilized barley seed that was not inoculated with the pathogen was placed beside each seed in the control.

Foliar and root disease symptom evaluation. Disease evaluation was based on Fusarium yellows and Fusarium yellowing decline symptoms. The severity scale used to assess foliar disease symptoms in the study was as follows: $0=$ no disease; $1=$ leaves wilted, small chlorotic areas on lower leaves, most of leaf green; 2 = leaves showing interveinal yellowing; 3 = leaves with small areas of necrosis or becoming necrotic and dying, less than half of the leaves affected; $4=$ more than half of leaves dead, plant stunted, most living leaves showing symptoms; and 5 = plant death (Hanson et al. 2009). Disease severity ratings were taken every week for 5 weeks after inoculation.

Five weeks after inoculation, plants were carefully removed from pots and washed under tap water, and roots were longitudinally cut to check for discoloration within the vascular system. The severity scale used for root symptom rating was as follows: $0=$ no internal browning; $1=$ slight internal browning, usually at the tip of the tap root; $2=$ moderate to severe internal browning of the entire tap root; and $3=$ severe internal browning extending from the tap root into the lower stem above the soil line (Rowe 1980).

Data analysis. Analysis of variance-type statistic test. Levene's test was first used to determine whether the data sets for disease severity had homogeneous variances and could be combined for analyses. Then, data were analyzed by a nonparametric method, using the rank and mixed procedures of SAS (version 9.4; SAS Institute Inc.). Data from foliar and root symptoms were ranked separately using the rank procedure and analysis of variance (ANOVA)-type statistics

Table 1. Test statistics for the effect of five different inoculation methods and two Fusarium spp. on foliar disease severity of sugar beet at 7, 14, 21, 28, and 35 days after inoculation

\begin{tabular}{lllrr}
\hline & \multicolumn{4}{c}{$\begin{array}{c}\text { Analysis of variance-type statistics } \\
(\text { ATS })^{\mathbf{a}}\end{array}$} \\
\cline { 2 - 6 } Effect & $\boldsymbol{d} \boldsymbol{f}_{\boldsymbol{N}}$ & $\boldsymbol{d} \boldsymbol{f}_{\boldsymbol{D}}$ & ATS & $\boldsymbol{P}$ value \\
\hline Isolate & 1 & 1 & 28.78 & $<0.0001$ \\
Inoculation method & 3.35 & 1 & 27.98 & $<0.0001$ \\
Isolate $\times$ inoculation method & 3.35 & 4.09 & 5.54 & 0.0005 \\
Time & 2.85 & 1 & 400.14 & $<0.0001$ \\
Isolate $\times$ time & 2.85 & 1 & 11.03 & $<0.0001$ \\
Inoculation method $\times$ time & 7.52 & 1 & 9.15 & $<0.0001$ \\
Isolate $\times$ inoculation method $\times$ time & 7.52 & 1 & 3.02 & 0.0028 \\
\hline
\end{tabular}

${ }^{\mathrm{a}} d f_{\mathrm{N}}=$ numerator degrees of freedom and $d f_{\mathrm{D}}=$ denominator degrees of freedom.

Table 2. Test statistics for the effect of five different inoculation methods and two Fusarium spp. on disease severity of sugar beet root at 35 days after inoculation

\begin{tabular}{lllll}
\hline & \multicolumn{4}{c}{$\begin{array}{c}\text { Analysis of variance-type statistics } \\
(\mathbf{A T S})^{\mathbf{a}}\end{array}$} \\
\cline { 2 - 5 } Effect & $\boldsymbol{d} \boldsymbol{f}_{\boldsymbol{N}}$ & $\boldsymbol{d} \boldsymbol{f}_{\boldsymbol{D}}$ & $\mathbf{A T S}$ & $\boldsymbol{P}$ value \\
\hline Isolate & 1 & 47.9 & 49.54 & $<0.0001$ \\
Inoculation method & 2.24 & 47.9 & 24.6 & $<0.0001$ \\
Isolate $\times$ inoculation method & 2.24 & 47.9 & 10.85 & $<0.0001$
\end{tabular}

${ }^{\mathrm{a}} d f_{\mathrm{N}}=$ numerator degrees of freedom and $d f_{\mathrm{D}}=$ denominator degrees of freedom. 
(ATS) analysis was conducted using the mixed procedure. For foliar data, the significance of the main effects of isolate, inoculation method, timing of observation, and their interactions were evaluated. For root data, the main effects of isolate, inoculation method, and their interactions were evaluated. SAS macros F2_LD_F1 and LD_ CI were used to calculate relative treatment effects and their $95 \%$ confidence intervals (Shah and Madden 2004).

Data transformation. To assess the rate of foliar symptom severity progress through time after inoculation, a foliar (leaf) symptom severity scale at each observation point was normalized to the maximum scale of 5 expressed as a percent. We called this transformed symptom severity the normalized symptom severity. For example, if a plant was evaluated with a leaf symptom scale of 2 , the normalized leaf symptom severity $\left(\mathrm{NS}_{\mathrm{L}} \%\right)$ was $(2 \div 5) \times 100$, which came to be $40 \%$.

The root symptom severity was assessed at the end of the experiments and the maximum root score of 3 was used to normalize the data. So, if the root symptom was scored 2 for a plant, the normalized root symptom severity expressed as a percent $\left(\mathrm{NS}_{\mathrm{R}} \%\right)$ was $(2 \div 3) \times$ 100 , which came to be $66.67 \%$.

The normalized symptom severity values of $\mathrm{NS}_{\mathrm{L}} \%$ and $\mathrm{NS}_{\mathrm{R}} \%$ observed at the end of the experiment were subjected to ANOVA. Mean normalized symptom severity value of each alternative inoculation was tested against the mean value of the standard root-dipping method as a control using Dunnett's method.

Fitting the Gompertz equation. The mean $\mathrm{NS}_{\mathrm{L}} \%$ value from each observation time point under each inoculation method in two experiments was fitted to the Gompertz model expressed as the following form (Tjørve and Tjørve 2017):

$$
y=A \times \exp \left\{-\exp \left[-b \times\left(D A I \times T_{i}\right)\right]\right\}
$$

in which $y$ is the $\mathrm{NS}_{\mathrm{L}}$ value expressed as a percent (i.e., $\mathrm{NS}_{\mathrm{L}} \%$ ), DAI is the days after inoculation, $A$ is the asymptotic value (i.e., the maximum relative disease severity), $b$ is the slope curvature parameter controlling the rate at which the disease severity progresses with time, and $T_{i}$ is the infection point of days after inoculation at which the slope is steepest (i.e., the rate of increase in disease is the highest). This model was fitted separately for the two isolates. Parameters were obtained using the nonlinear least squares method with the NLIN procedure of SAS (version 9.4; SAS Institute Inc.).

\section{Results}

The two runs of data for this study were combined because their homogeneity test for variance was not significantly different $(P>$ 0.67). The negative controls for each inoculation method were without foliar or root symptoms of Fusarium yellows or Fusarium yellowing decline and were not included in data analysis.

ATS for sugar beet disease severity based on foliar symptom observation is shown in Table 1. Inoculation methods and timing of observations resulted in significantly different foliage disease severity $(P<0.001)$. Isolates differed significantly in foliage disease symptom severity $(P<0.001)$. F . oxysporum f. betae F-19 caused a higher severity score than $F$. secorum 784-12-4. Importantly, the two-way and three-way interactions were all significant. Thus, an appropriate time point was chosen to assess the foliage disease severity between isolates among different inoculation methods. The ATS for root symptom severity was given in Table 2. Again, the root symptom severity significantly differed between the two isolates and among the five inoculation methods. Interaction of isolate with inoculation method on root symptom scores was also present $(P<0.001)$.

Foliar disease severity for all treatments of inoculated sugar beet at 7,14, 21, 28, and 35 days after inoculation (DAI) is shown in Table 3. The Gompertz model describing progress of normalized foliage symptom severity is shown in Figure 1 while the

Table 3. Effect of five different inoculation methods and two Fusarium spp. on foliar disease severity of sugar beet at 7, 14, 21, 28, and 35 days after inoculation $(\mathrm{DAI})^{\mathrm{a}}$

\begin{tabular}{|c|c|c|c|c|c|c|c|c|c|}
\hline \multirow[b]{2}{*}{ Method } & \multirow[b]{2}{*}{ DAI } & \multicolumn{2}{|c|}{$\mathbf{M D S}^{\mathbf{b}}$} & \multicolumn{2}{|c|}{$\mathbf{M R}^{\mathbf{c}}$} & \multicolumn{2}{|c|}{ REDS $^{\mathbf{d}}$} & \multicolumn{2}{|c|}{$95 \% \mathrm{CI}^{\mathrm{e}}$} \\
\hline & & F. oxy & F. sec & F. oxy & F. sec & F.oxy & $\overline{F . s e c}$ & F. oxy & F. sec \\
\hline Dipping & 7 & 0.00 & 0.00 & 122.50 & 122.50 & 0.203 & 0.203 & $0.187-0.220$ & $0.187-0.220$ \\
\hline Dipping & 14 & 4.00 & 3.00 & 373.33 & 332.66 & 0.621 & 0.554 & $0.562-0.677$ & $0.510-0.596$ \\
\hline Dipping & 21 & 5.00 & 4.50 & 487.08 & 452.99 & 0.811 & 0.754 & $0.752-0.858$ & $0.693-0.806$ \\
\hline Dipping & 28 & 5.00 & 5.00 & 501.75 & 482.24 & 0.835 & 0.803 & $0.801-0.865$ & $0.750-0.846$ \\
\hline Dipping & 35 & 5.00 & 5.00 & 501.75 & 491.98 & 0.835 & 0.819 & $0.801-0.865$ & $0.774-0.857$ \\
\hline Drenching & 7 & 0.00 & 0.00 & 122.50 & 122.50 & 0.203 & 0.203 & $0.187-0.220$ & $0.187-0.220$ \\
\hline Drenching & 14 & 0.00 & 0.00 & 146.63 & 134.60 & 0.244 & 0.223 & $0.196-0.300$ & $0.186-0.266$ \\
\hline Drenching & 21 & 1.00 & 0.00 & 240.40 & 210.57 & 0.400 & 0.350 & $0.295-0.516$ & $0.257-0.456$ \\
\hline Drenching & 28 & 2.00 & 1.50 & 328.01 & 272.01 & 0.546 & 0.452 & $0.403-0.681$ & $0.366-0.542$ \\
\hline Drenching & 35 & 3.50 & 3.00 & 402.30 & 308.44 & 0.670 & 0.513 & $0.575-0.753$ & $0.424-0.601$ \\
\hline Cutting & 7 & 0.00 & 0.00 & 122.50 & 122.50 & 0.203 & 0.203 & $0.187-0.220$ & $0.187-0.220$ \\
\hline Cutting & 14 & 0.00 & 0.00 & 134.59 & 149.15 & 0.223 & 0.248 & $0.186-0.267$ & $0.195-0.309$ \\
\hline Cutting & 21 & 3.50 & 1.00 & 323.36 & 257.28 & 0.538 & 0.428 & $0.396-0.674$ & $0.336-0.526$ \\
\hline Cutting & 28 & 5.00 & 3.00 & 367.30 & 280.68 & 0.611 & 0.467 & $0.434-0.762$ & $0.378-0.558$ \\
\hline Cutting & 35 & 5.00 & 3.00 & 438.55 & 307.42 & 0.730 & 0.512 & $0.590-0.834$ & $0.414-0.608$ \\
\hline Barley to root & 7 & 0.00 & 0.00 & 122.50 & 122.50 & 0.203 & 0.203 & $0.187-0.220$ & $0.187-0.220$ \\
\hline Barley to root & 14 & 2.50 & 0.00 & 304.56 & 122.50 & 0.507 & 0.203 & $0.394-0.619$ & $0.187-0.220$ \\
\hline Barley to root & 21 & 5.00 & 0.00 & 435.87 & 176.48 & 0.726 & 0.293 & $0.613-0.814$ & $0.223-0.376$ \\
\hline Barley to root & 28 & 5.00 & 1.00 & 467.65 & 236.03 & 0.778 & 0.393 & $0.715-0.830$ & $0.313-0.479$ \\
\hline Barley to root & 35 & 5.00 & 3.00 & 496.93 & 334.72 & 0.827 & 0.557 & $0.775-0.869$ & $0.518-0.596$ \\
\hline Barley to seed & 7 & 0.00 & 0.00 & 122.50 & 122.50 & 0.203 & 0.203 & $0.187-0.220$ & $0.187-0.220$ \\
\hline Barley to seed & 14 & 0.50 & 2.00 & 241.33 & 280.38 & 0.401 & 0.466 & $0.275-0.543$ & $0.333-0.604$ \\
\hline Barley to seed & 21 & 5.00 & 4.50 & 454.67 & 357.61 & 0.757 & 0.595 & $0.629-0.850$ & $0.425-0.744$ \\
\hline Barley to seed & 28 & 5.00 & 5.00 & 511.50 & 450.06 & 0.852 & 0.749 & $0.834-0.867$ & $0.632-0.837$ \\
\hline Barley to seed & 35 & 5.00 & 5.00 & 511.50 & 493.79 & 0.852 & 0.822 & $0.834-0.867$ & $0.758-0.871$ \\
\hline
\end{tabular}

a Fusarium oxysporum (F. oxy) and F. secorum (F. sec).

${ }^{\mathrm{b}}$ Median disease rating. Disease severity was evaluated every week for 5 weeks based a 0 -to- 5 scale, where $0=$ no disease; $1=$ leaves wilted, small chlorotic areas on lower leaves, most of leaf green; $2=$ leaves showing interveinal yellowing; $3=$ leaves with small areas of necrosis or becoming necrotic and dying, less than half of the leaves affected; $4=$ more than half of leaves dead, plant stunted, most living leaves showing symptoms; and $5=$ plant death.

c Mean rank.

${ }^{\mathrm{d}}$ Relative effect of disease severity.

e Upper and lower values of $95 \%$ confidence interval (CI) of relative effect. 
respective parameter estimates are given in Table 4 . With majority of the inoculation methods, leaf symptoms caused by two Fusarium spp. were first observed at $14 \mathrm{DAI}$, except for the treatments with $F$. secorum using the barley to root method, where symptoms were first observed at 21 DAI. Root-dipping, barley to root, and barley to seed had a similar high rate of increase in foliar symptoms. For the barley to root inoculation method, the use of F. secorum resulted in significantly lower disease development than $F$. oxysporum f. betae.

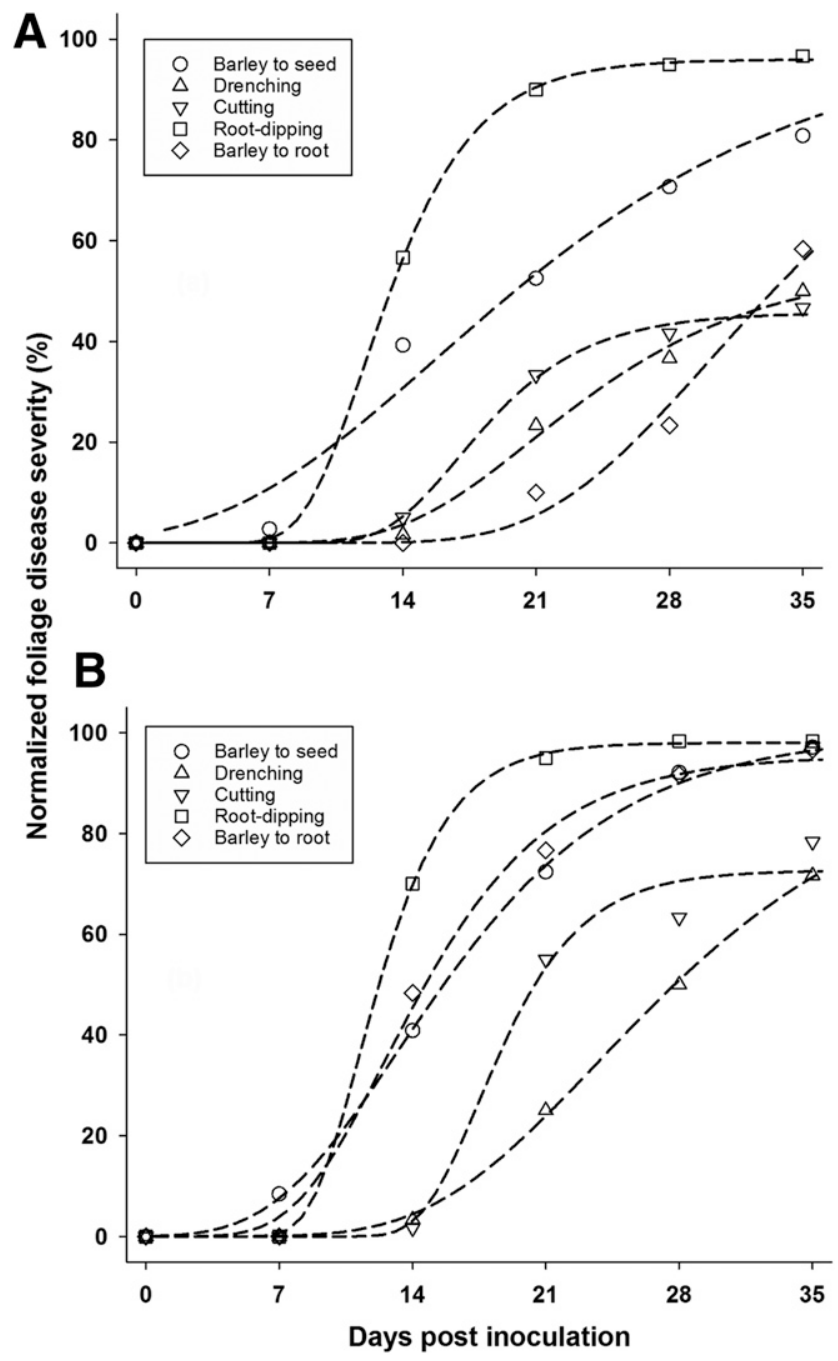

Fig. 1. Normalized foliage symptom severity progress through time post inoculation with five inoculation methods with A, Fusarium secorum 784-12-4 and B, F. oxysporum f. betae F-19.
Root disease severity for all the treatments of inoculated plants at 35 DAI is shown in Table 5. Among all of the treatments, rootdipping and barley to seed with both species and barley to root with $F$. oxysporum f. betae resulted in the highest similar disease severities. However, F. secorum 784-12-4, via barley to root inoculation, did not induce root symptoms similar to $F$. oxysporum f. betae. Cutting with $F$. oxysporum $\mathrm{f}$. betae was not significantly different from root-dipping and barley to seed methods, with a lower infection on sugar beet roots, but the disease severity was low with $F$. secorum 784-12-4. Drenching induced root symptoms but was inconsistent.

$\mathrm{NS}_{\mathrm{L}} \%$ and $\mathrm{NS}_{\mathrm{R}} \%$ caused by each isolate at $35 \mathrm{DAI}$ using the standard root-dipping inoculation method were compared with those using each of the four alternative inoculation methods from ANOVA. Regarding foliage symptom severity by $F$. secorum $784-12-4$, barley to seed inoculation did not differ significantly from the standard rootdipping inoculation $(P>0.05)$ whereas the standard root-dipping method resulted in significantly higher $\mathrm{NS}_{\mathrm{L}} \%$ than the other three alternative methods (Table 6). However, regarding foliage symptom severity by $F$. oxysporum $\mathrm{f}$. betae $\mathrm{F}-19$, the standard root-dipping method did not cause significantly higher $\mathrm{NS}_{\mathrm{L}} \%$ than any of the four alternative inoculation methods $(P>0.05)$ (Table 6). Similarly, the $\mathrm{NS}_{\mathrm{R}}$ expressed as a percent (i.e., $\mathrm{NS}_{\mathrm{R}} \%$ ) was not significantly different between root-dipping and barley to seed inoculation methods with $F$. secorum 784-12-4, or significantly different between rootdipping and all four alternative inoculation methods (Table 7).

\section{Discussion}

The standard root-dipping method was the most effective inoculation method for both Fusarium spp. inoculation on sugar beet. The root-dipping method included soaking seedlings in spore suspension followed by transplanting. During this process, spores could directly get in contact with the damaged root system and lead to pathogens entering the vascular system through wounds. Therefore, rootdipping allowed the pathogens to avoid resistance mechanisms at the root epidermal level (Eynck et al. 2009; Michielse and Rep 2009). Studies showed that F. oxysporum $\mathrm{f}$. betae could directly penetrate the root epidermis after forming and accumulating net-like hyphae on the surface of root tips, then colonize tissues intracellularly and intercellularly (Bishop and Cooper 1983; Czymmek et al. 2007; Mendgen et al. 1996; Van Peer and Schippers 1992). This also explains why drench inoculation without injury (drenching) and with injury (cutting) caused the same level of disease symptom severity. However, these two inoculation methods caused significantly lower foliage disease severity than the standard root-dipping method with F. secorum 784-12-4. Spore distribution in soil is limited by spore morphology and electrical charge, and by soil physical features (Hepple 1960; Wallace 1978). The study by Gracia-Garza and Fravel (1998) showed that spores were unevenly distributed in soil, and CFU at a depth of 0 to $2 \mathrm{~cm}$ were 10 times higher than at 8 to $10 \mathrm{~cm}$. The low disease severity observed in drench treatments in our study may be due to the fact that the majority of the spores applied in the drench treatment remained on the surface and in the top $2 \mathrm{~cm}$ of the soil, which reduced the chance of spores getting in

Table 4. Effect of five different inoculation methods and two Fusarium spp. on root disease severity of sugar beet at 35 days after inoculation (DAI)

\begin{tabular}{|c|c|c|c|c|c|c|c|c|}
\hline \multirow[b]{2}{*}{ Method } & \multicolumn{2}{|c|}{$\mathbf{M D S}^{\mathbf{b}}$} & \multicolumn{2}{|c|}{$\mathbf{M R}^{\mathrm{c}}$} & \multicolumn{2}{|c|}{ REDS $^{\mathbf{d}}$} & \multicolumn{2}{|c|}{$95 \% \mathrm{CI}^{\mathrm{e}}$} \\
\hline & F. oxy & F. sec & F. oxy & F. sec & F. oxy & F. sec & F.oxy & F. sec \\
\hline Dipping & 3 & 3 & 80.50 & 80.50 & 0.667 & 0.667 & $0.641-0.691$ & $0.641-0.691$ \\
\hline Drenching & 3 & 2 & 56.04 & 32.50 & 0.463 & 0.267 & $0.337-0.595$ & $0.177-0.391$ \\
\hline Cutting & 3 & 2 & 63.63 & 27.04 & 0.526 & 0.221 & $0.392-0.656$ & $0.149-0.327$ \\
\hline Barley to root & 3 & 1 & 80.50 & 23.29 & 0.667 & 0.190 & $0.641-0.691$ & $0.122-0.302$ \\
\hline Barley to seed & 3 & 3 & 80.50 & 80.50 & 0.667 & 0.667 & $0.641-0.691$ & $0.641-0.691$ \\
\hline
\end{tabular}

a Fusarium oxysporum (F. oxy) and F. secorum (F. sec).

b Median disease rating. Sugar beet plants were hand harvested at 35 DAI and root disease severity was rated with a 0 -to- 3 scale, where $0=$ no internal browning, $1=$ slight internal browning, usually at the tip of the tap root, $2=$ moderate to severe internal browning of the entire tap root, and $3=$ severe internal browning extending from the tap root into the lower stem above the soil line.

${ }^{c}$ Mean rank.

${ }^{d}$ Relative effect of disease severity.

${ }^{\mathrm{e}}$ Upper and lower values of $95 \%$ confidence interval (CI) of relative effect. 
contact with sugar beet roots and, thus, resulted in low disease severity.

Barley-based inoculum has been used to study the effect soilborne pathogens such as $R$. solani on sugar beet before (Gaskill 1968; Kirk et al. 2008; Noor and Khan 2014). In our study, Fusarium-colonized barley inoculum placed by the sugar beet seed at planting time caused the highest disease severity, with symptoms being observed as early as 7 DAI compared with the 14 DAI for standard root-dipping

Table 5. Estimate values for parameters in the Gompertz equation (i.e., equation 1) for each combination of two isolates with five inoculation methods

\begin{tabular}{lrccc}
\hline Isolate, inoculation method & $\boldsymbol{A}^{\mathbf{a}}$ & $\boldsymbol{b}^{\mathbf{b}}$ & $\boldsymbol{T}_{\boldsymbol{i}}^{\mathbf{c}}$ & $\boldsymbol{R}^{\mathbf{2}}$ \\
\hline Fusarium secorum 784-12-4 & & & & \\
$\quad$ Dipping & 95.992 & 0.314 & 11.984 & 1.000 \\
$\quad$ Drenching & 55.084 & 0.148 & 20.738 & 0.974 \\
Cutting & 45.739 & 0.267 & 16.892 & 0.998 \\
$\quad$ Barley to root & 100.000 & 0.115 & 30.243 & 0.984 \\
$\quad$ Barley to seed & 100.000 & 0.090 & 15.815 & 0.974 \\
F. oxysporum f. betae F-19 & & & & \\
Dipping & 98.038 & 0.388 & 11.213 & 1.000 \\
Drenching & 93.697 & 0.115 & 23.710 & 0.999 \\
Cutting & 72.668 & 0.334 & 17.474 & 0.986 \\
$\quad$ Barley to root & 95.478 & 0.209 & 12.578 & 0.993 \\
$\quad$ Barley to seed & 100.000 & 0.152 & 13.226 & 0.999 \\
\hline
\end{tabular}

${ }^{a}$ Asymptotic value (i.e., the maximum relative disease severity).

${ }^{b}$ Slope curvature parameter controlling the rate at which the disease severity progresses with time.

${ }^{c}$ Infection point of days after inoculation at which the slope is steepest.

Table 6. Normalized foliage disease symptom severity (i.e., $\mathrm{NS}_{\mathrm{L}} \%$ ) from root-dipping method in comparison with four alternative inoculation methods at 35 days after inoculation $(\mathrm{DAI})^{\mathrm{a}}$

Isolate, root dipping versus Severity difference Significant at $5 \%$ level

\begin{tabular}{lcc}
\hline Fusarium secorum 784-12-4 & & $\mathrm{ns}$ \\
$\quad$ Barley to seed & 15.840 & $*$ \\
Barley to root & 38.330 & $*$ \\
Drenching & 46.670 & $*$ \\
$\quad$ Cutting & 50.000 & \\
F. oxysporum f. betae F-19 & & $\mathrm{ns}$ \\
$\quad$ Barley to seed & 1.230 & $\mathrm{~ns}$ \\
Barley to root & 1.670 & $\mathrm{~ns}$ \\
Drenching & 26.670 & $\mathrm{~ns}$ \\
Cutting & 20.000 & \\
\hline
\end{tabular}

a Mean $\mathrm{NS}_{\mathrm{L}} \%$ with root-dipping method at 35 DAI was $96.67 \%$ with $F$. secorum 784-12-4 and $98.33 \%$ with $F$. oxysporum f. betae $\mathrm{F}-19$; ns $=$ not significant.

Table 7. Normalized root disease symptom severity (i.e., $\mathrm{NS}_{\mathrm{R}} \%$ ) from rootdipping method in comparison with four alternative inoculation methods at 35 days after inoculation $(\mathrm{DAI})^{\mathrm{a}}$

\begin{tabular}{lcc}
\hline Isolate, root dipping versus & Severity difference & Significant at 5\% level \\
\hline Fusarium secorum $784-12-4$ & & \\
$\quad$ Barley to seed & 12.256 & $\mathrm{~ns}$ \\
Barley to root & 55.556 & $*$ \\
Drenching & 44.444 & $*$ \\
Cutting & 50.000 & $*$ \\
F. oxysporum f. betae F-19 & & \\
Barley to seed & 1.320 & $\mathrm{~ns}$ \\
Barley to root & 0.000 & $\mathrm{~ns}$ \\
Drenching & 0.000 & $\mathrm{~ns}$ \\
Cutting & 19.440 & $\mathrm{~ns}$ \\
\hline
\end{tabular}

${ }^{a}$ Mean $\mathrm{NS}_{\mathrm{R}} \%$ with root-dipping method at 35 DAI was $100 \%$ with $F$. secorum 784-12-4 and $100 \%$ with $F$. oxysporum f. betae F-19; ns = not significant. method, and did not allow for distinction between isolates. However, when placing the Fusarium-colonized barley seed by the roots of sugar beet plants, $F$. secorum caused significantly lower disease severity with delayed onset of symptoms (21 DAI) compared with $F$. oxysporum f. betae (14 DAI). Also, during this investigation, $F$. oxysporum $\mathrm{f}$. betae (F-19) grew faster and more abundantly on barley than $F$. secorum (784-12-4). Number of CFU for $F$. oxysporum $\mathrm{f}$. betae (F-19) was $4.8 \times 10^{5} \mathrm{CFU} / \mathrm{barley}$, which was 2.6 times higher than the number of CFU for $F$. secorum (784-12-4) (data not shown). Plant stage also had an effect on sugar beet disease severity, and younger plants were more susceptible than older plants.

Burlakoti et al. (2012) reported that different Fusarium spp. could have similar foliar symptoms at $60 \mathrm{DAI}$ but, when evaluating the diseased roots, the more-virulent isolates resulted in more vascular discoloration than the less-virulent ones. In this study, foliar symptoms were evaluated by using a scale to record the yellowing response at 0 , $7,14,21,28$, and 35 DAI contributing to disease severities for each Fusarium isolate. This evaluation method for foliar symptoms caused by Fusarium spp. could be reliable, because both foliar (Table 3 ) and root (Table 4 ) evaluations indicated that $F$. oxysporum f. betae (F-19) induced significantly higher disease severity than $F$. secorum isolate (784-12-4). Burlakoti et al. (2012) reported that $F$. secorum was more aggressive than $F$. oxysporum f. betae on sugar beet. However, the specific isolate number of $F$. secorum was unknown. Because $F$. secorum was a relatively new species (Rivera et al. 2008), the differentiation in pathogenicity and virulence among its isolates was still unclear. Given the fact that $F$. oxysporum $\mathrm{f}$. betae (F-19) was evaluated by Hill et al. (2011) as highly pathogenic to sugar beet, $F$. oxysporum $\mathrm{f}$. betae (F-19) could be more aggressive than the specific $F$. secorum isolate 784-12-4.

In conclusion, this study evaluated artificial inoculation methods to induce Fusarium diseases on sugar beet in greenhouse conditions. The results showed that both root-dipping and barley to seed were effective inoculation methods with both isolates when symptoms were assessed at 35 DAI that could be used for Fusarium study on sugar beet. However, for large-scale sugar beet germplasm-resistant selection, the root-dipping method is time consuming, labor intensive, and impractical for field study because this method requires transplanting after inoculation. Therefore, barley to seed can be an alternative inoculation method that could be used for Fusarium study on sugar beet.

\section{Literature Cited}

Bishop, C. D., and Cooper, R. M. 1983. An ultrastructural study of root invasion in three vascular wilt diseases. I. Colonization of susceptible cultivars. Physiol Plant Pathol. 23:323-343.

Burlakoti, P. 2007. Fusarium species associated with sugar beet grown in the Red River Valley: Pathogenicity, cultivar response, and baseline sensitivity to fungicides. Master thesis, North Dakota State University, Fargo, ND, U.S.A.

Burlakoti, P., Rivera, V., Secor, G. A., Qi, A., Del Rio-Mendoza, L. E., and Khan, M. F. 2012. Comparative pathogenicity and virulence of Fusarium species on sugar beet. Plant Dis. 96:1291-1296.

Czymmek, K. J., Fogg, M., Powell, D. H., Sweigard, J., Park, S. Y., and Kang, S. 2007. In vivo time-lapse documentation using confocal and multi-photon microscopy reveals the mechanisms of invasion into the Arabidopsis root vascular system by Fusarium oxysporum. Fungal Genet. Biol. 44:1011-1023.

Das, I. K., Rakshit, S., and Patil, J. V. 2015. Assessment of artificial inoculation methods for development of sorghum pokkah boeng caused by Fusarium subglutinans. Crop Prot. 77:94-101.

Dowd, C., Wilson, I. W., and McFadden, H. 2004. Gene expression profile changes in cotton root and hypocotyl tissues in response to infection with Fusarium oxysporum f. sp. vasinfectum. Mol. Plant-Microbe Interact. 17:654-667.

Eynck, C., Koopmann, B., and Von Tiedemann, A. 2009. Identification of Brassica accessions with enhanced resistance to Verticillium longisporum under controlled and field conditions. J. Plant Dis. Prot. 116:63-72.

FAO. 2017. Food and Agricultural Organization Statistics. Food and Agriculture Organization of the United Nations. http://www.fao.org/faostat/en/\#data/QC/visualize

Gaskill, J. O. 1968. Breeding for Rhizoctonia resistance in sugar beet. J. Sugar Beet Res. 15:107-119.

Gracia-Garza, J. A., and Fravel, D. R. 1998. Effect of relative humidity on sporulation of Fusarium oxysporum in various formulations and effect of water on spore movement through soil. Phytopathology 88:544-549.

Hanson, L. E. 2006. First report of Fusarium yellows of sugar beet caused by Fusarium oxysporum in Michigan. Plant Dis. 90:1554. 
Hanson, L. E., and Hill, A. L. 2004. Fusarium species causing Fusarium yellows of sugar beet. J. Sugar Beet Res. 41:163-178.

Hanson, L. E., Hill, A. L., Jacobsen, B. J., and Panella, L. 2009. Response of sugar beet lines to isolates of Fusarium oxysporum $\mathrm{f}$. sp. betae from the United States. J. Sugar Beet Res. 46:11-26.

Hanson, L. E., and Jacobsen, B. J. 2009. Fusarium yellows. Pages 28-29 in: Compendium of Beet Diseases and Pests. R. M. Harveson, L. E. Hanson, and G. L. Hein, eds. The American Phytopathological Society Press, St. Paul, MN, U.S.A.

Hepple, S. 1960. The movement of fungal spores in soil. Trans. Br. Mycol. Soc. 43:73-79.

Hill, A. L., Reeves, P. A., Larson, R. L., Fenwick, A. L., Hanson, L. E., and Panella, L. 2011. Genetic variability among isolates of Fusarium oxysporum from sugar beet. Plant Pathol. 60:496-505.

Khan, M. F., Bradley, C. A., and Windels, C. E. 2009. Fusarium Yellows of Sugar Beet. PP-1247. North Dakota State University Extension Service, Fargo, ND, U.S.A.

Kirk, W. W., Wharton, P. S., Schafer, R. L., Tumbalam, P., Poindexter, S., Guza, C., Fogg, R., Schlatter, T., Stewart, J., Hubbell, L., and Ruppal, D. 2008. Optimizing fungicide timing for the control of Rhizoctonia crown and root rot of sugar beet using soil temperature and plant growth stages. Plant Dis. 92:1091-1098.

Liu, Y., and Khan, M. F. 2016. Penthiopyrad applied in close proximity to Rhizoctonia solani provided effective disease control in sugar beet. Crop Prot. 85:33-37.

Maitlo, S. A., Syed, R. N., Rustamani, M. A., Khuhro, R. D., and Lodhi, A. M. 2016. Influence of inoculation methods and inoculum levels on the aggressiveness of Fusarium oxysporum f. sp. ciceris on chickpea and plant growth. Int. J. Agric. Biol. 18:31-36.

Mendgen, K., Hahn, M., and Deising, H. 1996. Morphogenesis and mechanisms of penetration by plant pathogenic fungi. Annu. Rev. Phytopathol. 34:367-386.

Michielse, C. B., and Rep, M. 2009. Pathogen profile update: Fusarium oxysporum. Mol. Plant Pathol. 10:311-324.

Niehaus, W. S. 2016. Results of American Crystal's 2016 Official Coded Variety Trials. Sugarbeet Research and Education Board. https://www.sbreb.org/wpcontent/uploads/2018/02/ResultsCodedVarietyTrials2016.pdf
Noor, A., and Khan, M. F. R. 2014. Efficacy and safety of mixing azoxystrobin and starter fertilizers for controlling Rhizoctonia solani in sugar beet. Phytoparasitica 43:51-55.

Rivera, V., Rengifo, J., Khan, M., Geiser, D. M., Mansfield, M., and Secor, G. 2008. First report of a novel Fusarium species causing yellowing decline of sugar beet in Minnesota. Plant Dis. 92:1589.

Rowe, R. C. 1980. Comparative pathogenicity and host ranges of Fusarium oxysporum isolates causing crown and root rot of greenhouse and fieldgrown tomatoes in North America and Japan. Phytopathology 70: 1143-1148.

Secor, G. A., Rivera-Varas, V., Christ, D. S., Mathew, F. M., Khan, M. F., Varrelmann, M., and Bolton, M. D. 2014. Characterization of Fusarium secorum, a new species causing Fusarium yellowing decline of sugar beet in north central USA. Fungal Biol. 118:764-775.

Shah, D. A., and Madden, L. V. 2004. Nonparametric analysis of ordinal data in designed factorial experiments. Phytopathology 94:33-43.

Tjørve, K. M. C., and Tjørve, E. 2017. A proposed family of unified models for sigmoid growth. Ecol. Modell. 359:117-127.

USDA-ERS. 2019. Sugar and Sweeteners Yearbook Tables. United States Department of Agriculture-Economic Research Service. https://www.ers.usda gov/data-products/sugar-and-sweeteners-yearbook-tables/sugar-and-sweetenersyearbook-tables/\#U.S

Vakalounakis, D. J. 1996. Root and stem rot of cucumber caused by Fusarium oxysporum f. sp. radicis-cucumerinum f. sp. nov. Plant Dis. 80:313-316.

Van Peer, R., and Schippers, B. 1992. Lipopolysaccharides of plant-growth promoting Pseudomonas sp. strain WCS417r induce resistance in carnation to Fusarium wilt. Eur. J. Plant Pathol. 98:129-139.

Wallace, H. R. 1978. Dispersal in time and space: Soil pathogens. Pages 181-202 in: Plant Disease, An Advanced Treatise. J. G. Horsfall and E. B. Cowling, eds. Academic Press, New York, NY, U.S.A

Windels, C. E., Brantner, J. R., Bradley, C. A., and Khan, M. F. R. 2005. First report of Fusarium oxysporum causing yellows on sugar beet in the Red River Valley of Minnesota and North Dakota. Plant Dis. 89:341. 